\title{
Immunoblasts in synovial fluid and blood in the rheumatic diseases
}

\author{
ALI ASGHAR EGHTEDARI*, PAULA. BACON, AND ANTHONY COLLINS \\ From the Arthritis and Rheumatism Council Research Unit, Royal National Hospital for Rheumatic Diseases, \\ Bath
}

SUMMARY Synovial fluid studies have been made on 43 patients with rheumatic disease. Lymphocytes separated by a 2-stage procedure were examined for the presence of activated large lymphoid cells or immunoblasts. Such immunoblasts were found in 19 of 21 patients with classical rheumatoid arthritis and 7 of 10 patients with seronegative polyarthritis, including patients with Still's disease, psoriatic arthritis, and ankylosing spondylitis. No immunoblasts were seen in synovial fluid from osteoarthrosis or in the inflammatory but nonimmune synovial fluid from crystal-induced arthritis. The presence of immunoblasts showed a correlation with the lymphocyte count in the synovial fluid but not with the total white cell count. Preliminary studies confirm the spontaneous metabolic activity of these cells by autoradiography and show them by scanning electron microscopy to have a villous surface membrane. Simultaneous peripheral blood studies showed a lower incidence of immunoblasts than in the synovial fluid. It is suggested that these cells originate in the synovial membrane. In view of the known migration characteristic of immunoblasts these cells may be important in the spread of immune arthritis as well as being markers of disease activity.

Abnormalities of peripheral blood lymphoid cells have been described in rheumatoid arthritis and other connective tissue diseases, notably the presence of increased numbers of medium sized lymphocytes and plasma cells as well as activated lymphoid cells or immunoblasts. ${ }^{1}$ These latter are larger pyroninophilic lymphoid cells, $15-25 \mu \mathrm{m}$ in diameter with a prominent Hof near the nuclear indentation. They are metabolically active cells which take up tritiated thymidine. ${ }^{2}$ Increased numbers of peripheral blood immunoblasts have recently also been demonstrated in certain seronegative disorders, such as ankylosing spondylitis ${ }^{3}$ and polymyalgia rheumatica. ${ }^{4}$ In each case the number of immunoblasts was related to the degree of disease activity as assessed both clinically and by other laboratory tests.

The origin of the peripheral blood immunoblasts is unknown, but similar cells are seen after infection ${ }^{5}$ or immunisation. ${ }^{6}$ In rheumatoid disease the clini-

Accepted for publication 23 May 1979

Correspondence to Dr P. A. Bacon, Royal National Hospital for Rheumatic Diseases, Upper Borough Walls, Bath BA1 $1 \mathrm{R} 1$.

*Current address: Department of Medicine, Pahlavi University, Shiraz, Iran. cally obvious site of active inflammation is the synovial membrane and lymphoid cells are known to be important in the production of the synovitis. ${ }^{7}$ A study of synovial fluid lymphoid cells was therefore set up to look for the presence of similar immunoblasts in synovial fluid and to correlate this with the concurrent peripheral blood picture.

\section{Materials and methods}

Synovial fluid was obtained by closed aspiration of the knee joint from a total of 43 patients. Twentyone patients had a classical or definite seropositive rheumatoid arthritis. Ten patients had a seronegative polyarthritis; 3 of these had psoriatic arthritis, 2 had seronegative rheumatoid arthritis. Of the remaining patients 1 each had Still's disease, Reiter's disease, and ankylosing spondylitis, and 2 had polymyalgia rheumatica with synovitis. Three patients had an inflammatory nonimmune synovitis due to chondrocalcinosis, confirmed by the finding of calcium pyrophosphate crystals in the synovial fluid. Nine patients had osteoarthrosis with synovial effusion, with no evidence of an inflammatory component. 
SYNOVIAL FLUID STUDIES

A total and differential white cell count was performed on synovial fluids. Lymphocytes were separated and purified by a 2-stage separation technique. Synovial fluid was treated with hyaluronidase $(0.2 \mathrm{ml}$ per $20 \mathrm{ml}$ effusion for 15 minutes at $37^{\circ} \mathrm{C}$ ). The cells were then washed and resuspended in Eagle's TC 199 medium before separation over a Ficol-Hypaque gradient. The lymphoid cells from the interface layer were again washed in TC 199 and resuspended with carbonyl iron and methyl cellulose at $37^{\circ} \mathrm{C}$ for 30 minutes in a shaking water bath to remove phagocytic cells. The lymphocyte preparation was stained with Wright's stain. At least 500 lymphoid cells were counted, and the percentage of immunoblasts was recorded. Peripheral blood studies were made simultaneously. Lymphocyte separation was by modification of the method of Coulson and Chalmers ${ }^{8}$ as described previously. Metabolic activity was confirmed in $\mathbf{3}$ cases by tritiated thymidine. Scanning electron microscopy was performed with a Pye Cambridge S4 Stereoscan after fixation. The cells were fixed $1 \%$ glutaraldehyde $0 \cdot 15 \mathrm{M}$ phosphate buffer, $\mathrm{pH} 7 \cdot 2$, for 2 hours followed by $1 \% \mathrm{NA}$ cacodylate, $\mathrm{pH}$ 7.4 , for 30 minutes. The cells were dehydrated in ethyl alcohol and embedded on an aluminium cap.

\section{Results}

The 2-step method of purifying synovial fluid lymphocytes, utilising both Ficol-Hypaque and methyl cellulose carbonyl iron, gives clean preparations containing at least $98 \%$ lymphocytes. An activated large lymphoid cell, or immunoblast, stands out clearly from the other small lymphocytes (Fig. 1). The percentage of immunoblasts in synovial fluids from the different patient groups is shown in Fig. 2. In inflammatory polyarthritis the majority of synovial fluids contained immunoblasts in contrast to the absence of these cells in noninflammatory fluids in osteoarthrosis. Nineteen out of 21 patients with rheumatoid arthritis showed positive synovial fluid immunoblasts, as did 7 out of 10 patients with seronegative arthritis. The 3 patients with inflammatory nonimmune arthritis due to chondrocalcinosis all failed to show immunoblasts, though there were lymphoid cells in the synovial fluid. The total cell count together with the numbers of polymorphs and lymphocytes in the synovial fluid in the different groups is shown in Table 1. The total cell count is, as expected, highest in patients with rheumatoid arthritis, who also have the highest frequency of immunoblasts. However, there is virtually no difference in the total cell count between the patients with seronegative polyarthritis,

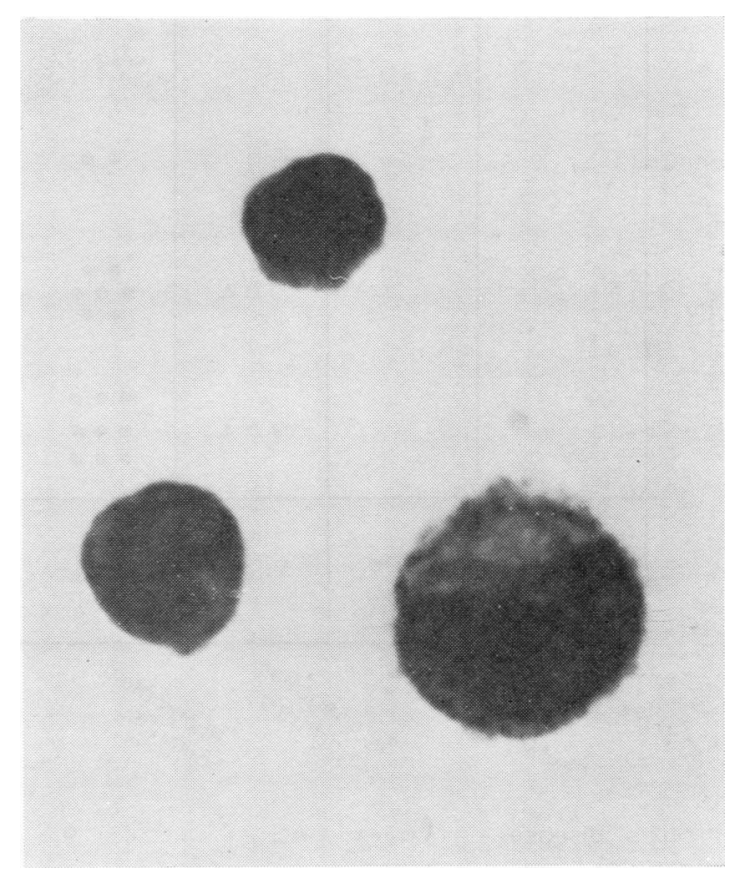

Fig. 1 The synovial fluid preparation. The large immunoblast stands out clearly in comparison to the small lymphocytes.

Table 1 Synovial fluid white cell count

\begin{tabular}{|c|c|c|c|c|}
\hline Cell count & $\begin{array}{l}\text { Osteo- } \\
\text { arthrosis, } \\
\text { mean } \\
\text { count }\end{array}$ & $\begin{array}{l}\text { Chondro- } \\
\text { calcinosis, } \\
\text { mean } \\
\text { count }\end{array}$ & $\begin{array}{l}\text { Seronegative } \\
\text { polyarthritis, } \\
\text { mean } \\
\text { count }\end{array}$ & $\begin{array}{l}\text { Rheumatoid } \\
\text { arthritis, } \\
\text { mean } \\
\text { count }\end{array}$ \\
\hline \multicolumn{5}{|c|}{$\begin{array}{l}\text { Total white cell } \\
\text { count (per }\end{array}$} \\
\hline $\mathrm{mm}^{3}$ & 630 & 4450 & 5650 & 11800 \\
\hline $\begin{array}{l}\text { Polymorphs } \\
\text { (percentage) }\end{array}$ & $\begin{array}{l}170 \\
(27)\end{array}$ & $\begin{array}{c}2830 \\
(63)\end{array}$ & $\begin{array}{r}2712 \\
(48)\end{array}$ & $\begin{array}{r}8260 \\
(70)\end{array}$ \\
\hline Lymphocytes & 365 & 979 & 2203 & 2242 \\
\hline
\end{tabular}

SI conversion: $10^{9} / 1=10^{3} / \mathrm{mm}^{3} \times 10^{6}$.

who did have immunoblasts, and these with chondrocalcinosis, who did not. The lymphocyte count in the synovial fluid correlates much better with the presence of immunoblasts. The total lymphocyte count was highest in patients with rheumatoid arthritis because of the higher total cell count, though the percentage of lymphocytes was lower. A similar lymphocyte count was found in patients with seronegative polyarthritis with a lower total white count.

The relationship between the numbers of immunoblasts in the synovial and the concurrent peripheral blood studies are shown in Fig. 3. In rheumatoid 


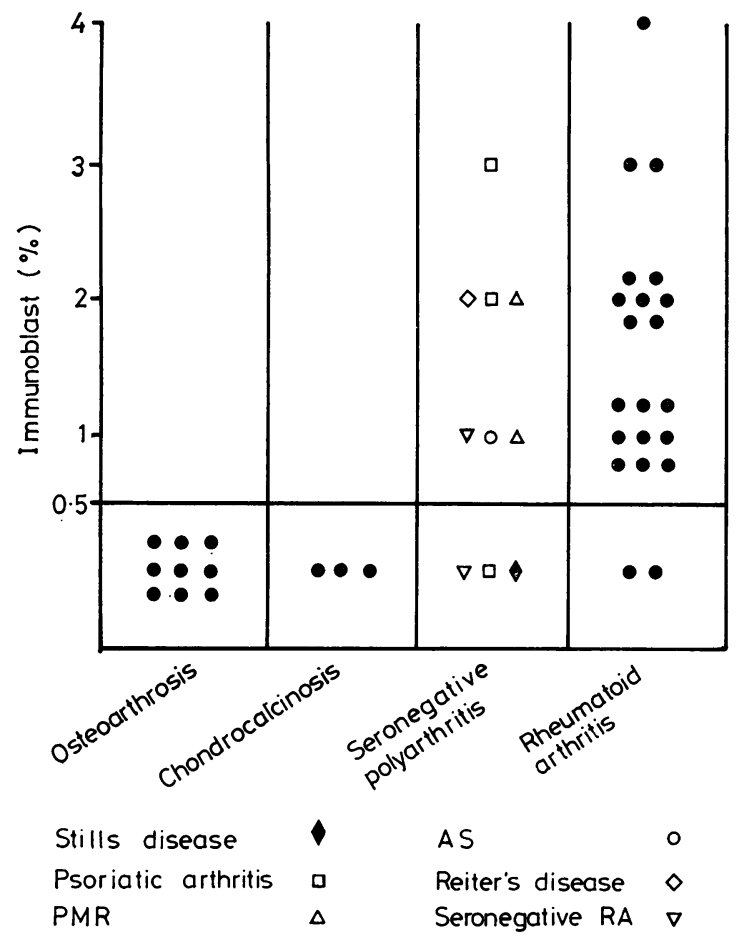

Fig. 2 Percentages of immunoblasts compared in the different disease states. Positive findings were confined to inflammatory immune arthritis.

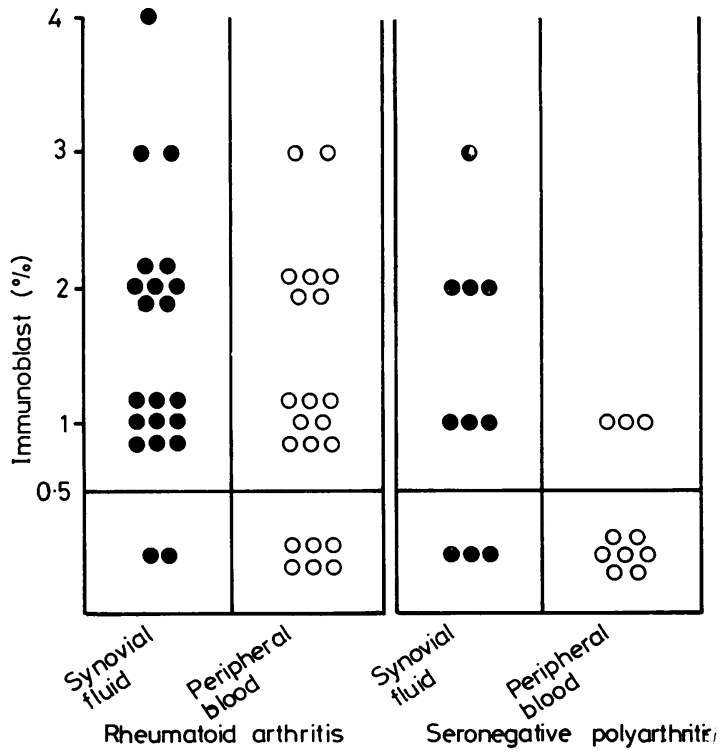

Fig. 3 Simultaneous estimations of synovial fluid of peripheral blood immunoblasts compared. In both RA and seronegative diseases the numbers were higher in the synovial fluid. arthritis the majority of patients were positive for immunoblasts in peripheral blood (15 out of 21$)$ as well as in synovial fluid. In seronegative polyarthritis the incidence of positive immunoblasts was lower in peripheral blood (3 out of 10) than in synovial fluid ( 7 out of 10). Taking the 2 groups of inflammatory arthritis together, we found 26 of 31 had positive synovial fluid findings as compared to 18 of 31 in the peripheral blood, but this difference does not reach statistical significance. However, no patient with a negative synovial fluid preparation had positive immunoblasts in the peripheral blood.

Only preliminary studies have been performed to establish the nature of these immunoblasts in synovial fluid. Metabolic activity has been confirmed in 3 cases with tritiated thymidine. An increased spontaneous uptake, in the absence of mitogens, was found by autoradiography. Scanning electron microscopy studies have been made on 10 specimens, all of which showed positive immunoblasts on microscopy. Large lymphoid cells were identified in all 10. A villous surface membrane was identified in these cells, but the density and complexity of the villi was not as great as that usually seen in normal B lymphoid cells.

\section{Discussion}

The 2-step method used here for isolation of cells from synovial fluid gives a much cleaner preparation of lymphocytes than the simple 1-step method used by previous authors. ${ }^{910}$ The Ficol-Hypaque gradient on its own allows incorporation of many mononuclear cells which seem to have the properties of macrophages. These are removed by incubation with carbonyl iron, leaving a virtually pure lymphocyte preparation. This has obvious advantages when trying to assess the morphology of different lymphoid populations. A similar 2-step method isolated lymphocytes of $99 \%$ purity from peripheral blood ${ }^{11}$ with no alteration in the percentage of subpopulations in spite of a marked loss of lymphocytes during purification. It is reasonable to assume that the same holds true for synovial fluid lymphocytes, though no direct experiments have been made to test this.

The results presented here show that immunoblasts are found in the synovial fluid of patients with active inflammatory arthritis of an 'autoimmune' and rheumatoid type. This seems to be true both for patients with classical seropositive rheumatoid arthritis and for the seronegative rheumatoid variants. These cells are not found in patients with non-inflammatory osteoarthrotic effusions even when adequate lymphoid cell isolations are made. The presence of immunoblasts does not 
seem to be due to inflammation as such, since they were not found in the patients with crystal-induced inflammatory arthritis. The presence of immunoblasts in each patient correlates with the total number of lymphocytes in the synovial fluid. This has previously been shown to be high in a seronegative arthritis such as ankylosing spondylitis. ${ }^{12}$ The number of immunoblasts does not correlate with the total synovial fluid white cell count, which is much higher in rheumatoid arthritis, but the majority of cells here are polymorphs.

Previous studies had shown that peripheral blood immunoblasts correlated with other evidence of disease activity. ${ }^{1}$ The number of rheumatoid patients showing peripheral blood immunoblasts was somewhat higher in the current study, in which the patients were selected because they had active disease with large synovial effusions. Even in this selected group with active disease the number of positive preparations was higher in the synovial fluid than in the peripheral blood, suggesting that the circulating immunoblasts might originate from within the joints. though direct studies of the migratory patterns of labelled cells would be needed to establish this point. Most events within the synovial fluid are secondary to those within the synovium itself. Immunoblasts are usually formed within lymphoid tissue, normally within lymph nodes or spleen..$^{13}$ It is known that the rheumatoid synovium contains large numbers of lymphoid cells, which may be aggregated into follicles, and appears to have the functions of an organised lymphoid tissue. ${ }^{14}$ It is reasonable to assume that the origin of synovial fluid immunoblasts is from lymphoid tissue within the synovium itself. Indeed, blast cells, largely plasmablasts, have been described in electron microscopy studies of rheumatoid synovium. ${ }^{15}$ It is possible that those in the peripheral blood also come from this source.

The nature of the immunoblasts found in synovial fluid has not been investigated in detail, though they appear to be metabolically active cells, a finding that confirms the previous findings in peripheral blood. ${ }^{1}$ The preliminary scanning EM pictures show a villous surface, which some authors believe is suggestive of a $B$ cell. ${ }^{16}$ This accords with the immunofluorescent finding of some B cells among circulating immunoblasts (Delbarre et al.,1975). However, the majority of circulating blast cells originate from T cells. ${ }^{17}$ In RA synovial fluid B lymphocytes are often depressed, ${ }^{18} 19$ and an increased number of null cells have been noted. The presence of activated immunoblasts, with temporary loss of surface markers, could contribute to the increased numbers of null cells, but further studies of these immunoblasts are required.
The current finding of immunoblasts in rheumatoid synovial fluid accords with previous evidence that synovial fluid lymphocytes are already precommitted. Increased spontaneous uptake of tritiated thymidine in the absence of stimulation has been noted ${ }^{20}$ together with poor responses to mitogens. ${ }^{21}$

The significance of the immunoblasts in rheumatoid disease is 2-fold. At a simple level their mere presence is another laboratory marker for disease activity. At a more fundamental level it is known that immunoblasts have different circulation patterns and homing abilities from those of normal lymphoid cells. In the lamina propria of the small gut they appear to penetrate the endothelium of normal small intestine. ${ }^{22}$ By analogy immunoblasts may be able to penetrate the endothelium of noninflamed synovial joints. It has been suggested that a random population of uncommitted mononuclear cells has a specific ability to engage with a target antigen. ${ }^{23}$ In the context of rheumatoid disease the immunoblasts may be cells capable of spreading synovial inflammation to noninflamed sites in other joints.

We thank the Arthritis and Rheumatism Council for financial support and Mrs Jane Crockett for skilled technical assistance.

\section{References}

1 Bacon P A, Sewell R L, Crowther D. Reactive lymphoid cells (immunoblasts) in autoimmune and haematological disorders. Clin Exp Immunol 1975; 19: 201-8.

2 Delbarre F, Le Go A, Kahan A. Hyperbasophilic immunoblasts in circulating blood in chronic inflammatory rheumatic and collagen diseases. Ann Rheum Dis 1975; 34: 422-30.

3 Eghtedari A A, Davis P, Bacon P A. Immunological reactivity in ankylosing spondylitis-Circulating immunoblasts, autoantibodies and immunoglobulins. Ann Rheum Dis 1976; 35: 155-7.

4 Eghtedari A A, Essellnckx W, Bacon P A. Circulating immunoblasts in polymyalgia rheumatica. Ann Rheum Dis 1976; 35: 158-61.

5 Crowther D, Fairley G H, Sewell R L. Significance of the changes in the circulating lymphoid cells in Hodgkin's disease. Br Med J 1969; 2: 473-7.

- Crowther D, Fairley G H, Sewell R L. Lymphoid cellular responses in the blood after immunization in man. $J$ Exp Med 1969; 129: 849-69.

7 Tannenbaum H, Pinkus G S, Anderson L G, et al. Immunological characterization of the mononuclear cell infiltrates in rheumatoid synovia, in rheumatoid nodules, and in 1ip biopsies from patients with Sjögren's syndrome. Arthritis Rheum 1975; 18: 305-14.

8 Coulson A S, Chalmers D G. Response of human blood lymphocytes to tuberculin PPD in tissue cultures. Immunology 1967; 12: 417-29.

- Loewi G, Dorling J, Howard A. Mononuclear cells from inflammatory joint effusions: electron microscopic appearances and immunoglobulins synthesis. $J$ Rheumatol 1974; 1 : 34-44. 
10 Takagusi K, Hollingsworth J W. Morphological studies on mononuclear cells of human synovial fluid. Arthritis Rheum 1967; 10: 495-501.

11 Holm G, Petterson D, Mellstedt H, et al. Lymphocyte sub-populations in peripheral blood of healthy persons. Characterization by surface markers and lack of selection during purification. Clin Exp Immunol 1975; 20: 443-58.

12 Kendall M J, Farr M, Maynell M J, et al. Synovial fluid in ankylosing spondylitis. Ann Rheum Dis 1973; 32: 487-92.

13 Hall J G. Observations on the migration and localisation of lymphoid cells. In: Progress in Immunology. Brent L, Holborow J H, eds. North Holland, 1974; 11 : 15-25.

14 Zvaifler N J. The immunopathology of joint inflammation in rheumatoid arthritis. Adv Immunol 1973; 16: 265-336.

15 Kobayashi I, Ziff M. Electron microscopic studies of lymphoid cells in the rheumatoid synovial membrane. Arthritis Rheum 1973; 16: 471-86.

16 Polliack A, Lampen N, Clarkson B D, et al. Identification of human $B$ and $T$ lymphocytes by scanning electron microscopy. J Exp Med 1973; 138: 607-24.

17 Van Boxel J A, Paget S A. Predominantly T-cell infiltrate in synovial membranes. $N$ Engl J Med 1975; 293: 517-20.
18 Frøland S S, Natvig J B, Husby G. Immunological characterization of lymphocytes in synovial fluid from patients with rheumatoid arthritis. Scand $J$ Immunol 1973; 2: 67-73.

19 Brennar A, Scheinberg M A, Cathcart E S. Surface characteristics of synovial fluid and peripheral blood lymphocytes in inflammatory arthritis. Arthritis Rheum 1975; 18: 297-303.

20 Stratton J A, Peters J B. Response of synovial fluid and peripheral blood lymphocytes to in vitro stimulation. Arthritis Rheum 1972; 15: 457 (abst).

21 Panayi G S. Response of rheumatoid-synovial-fluid lymphocytes to non-specific mitogens. Lancet 1973; ii: 512-3.

22 Parratt D M V, Ferguson A. Selective migration of lymphocytes within the mouse small intestine. Immunology 1974; 26: 571-88.

23 Glover D J, Hall J G, et al. The nature of blood-urine cytotoxic cells 1 . Co-operation between the white cells of the blood and lymph of sheep in the destruction of xenogenic tumour cells in vitro. Transplantation 1974; 17: $254-64$ 